\title{
Nuclear DNA content and chromatin pattern of rat rhabdomyosarcoma cell sublines with different metastatic potentials
}

\author{
Jean Dufer ${ }^{\mathrm{a}, *}$, Marie-France Poupon ${ }^{\mathrm{b}}$ and \\ Sonia Yatouji ${ }^{\mathrm{a}}$ \\ a Unité MéDIAN, CNRS-FRE 2141, IFR 53, Faculté \\ de Pharmacie, Université de Reims, 1 rue du \\ Maréchal Juin, 51100 Reims, France \\ ${ }^{\mathrm{b}}$ UMR 147 CNRS-IC, Institut Curie, 26 rue d'Ulm, \\ 75248 Paris, France
}

Received 26 September 1999

Accepted 14 February 2000

There is a constant need of features able to characterize potentially metastatic cells among the heterogeneous cell subpopulations which constitute a tumor. Image cytometry of metastatic tumor cells give rise to variable results, partly because of a heterogeneous origin of cells, or potential drug effects. The aim of this work was to characterize nuclear changes observed in metastatic cell clones issued in vitro from the same parental cell population The nuclear phenotypes of 6 cell sublines isolated from a rat rhabdomyosarcoma cell line and differing in their metastatic ability were evaluated by image cytometry on Feulgen-stained preparations. Densitometric [5], geometric [3] and textural [9] features were computed from each nuclear image. For each cell subline, a metastatic score, ranging from 0 to 10 , was calculated on the basis of in vivo invasivity data, by measuring the number of pulmonary metastases observed after s.c. graft of tumor cells in rats. Data obtained were compared to karyotype, growth characteristics, and oncogene expressions of cell lines. The nuclear DNA content, the chromosome numbers, the cell sublines doubling times, and the distribution of cells within the cell cycle appear unrelated with this score. On the contrary, increase in metastatic ability is accompanied by changes in chromatin pattern as assessed by textural features. Progressive increase in chromatin condensation can be observed in cell sublines with increasing metastatic

\footnotetext{
*Correspondence to: Jean Dufer, Unité MéDIAN, CNRS-FRE 2141, UFR Pharmacie, 1 rue du Maréchal Juin, F-51100 Reims, France. Tel./Fax: +33 32691 8015; E-mail: jean.dufer@univreims.fr.
}

score. These results were confirmed by an unsupervised multivariate partitioning of rhabdomyosarcoma cells which identified two separate subsets whose distributions within the analyzed cell lines correlate with their metastatic ability. These data suggest that, in rat rhabdomyosarcoma cell sublines, metastatic ability could be associated with nuclear morphological changes at the level of chromatin texture.

Keywords: Metastasis, image cytometry, nucleus, rat rhabdomyosarcoma

\section{Introduction}

In spite of significant improvements both in diagnosis and therapy, many deaths in cancer patients are due to metastases. As stated by Carr and Pettigrew [5], one of the most important question to ask about a human neoplasm is "Will it metastasize?". There is therefore a constant need of features able to characterize potentially metastatic cells among the heterogeneous cell subpopulations which constitute a tumor $[7,10,37,38]$.

A major advance in this field of metastasis research has come from the isolation of tumor cell subpopulations that display markedly different metastatic behavior. Some of these cell subpopulations, obtained by selection or transfection, have been accurately described and characterized in terms of biochemical properties and invasive activity $[1,34,36]$, but attempts to correlate the morphological features of these tumor cell sublines with their metastatic potential are scarce. Nevertheless, alterations in cell and particularly nuclear morphology have long been a hallmark of cancer pathology [33] and authors have suggested that these morphological phenomena could have predictive value [11]. Attention has been particularly focused on nuclear morphology, DNA content and chromatin structure $[6,43]$. In the context of metastatic potential, comparisons of mouse B16 melanoma cell lines revealed in highly metastatic variants an increased chromatin condensation [31], heterogeneity of DNA ploidy 
and an increased nuclear pleomorphism [25,26]. Moreover, fibroblasts transfected by the H-ras oncogene exhibited increased levels of chromatin condensation when compared to non-transformed cells [28,29] although it was difficult in this system to correlate directly chromatin changes, ras levels or metastatic ability [27].

Since rat rhabdomyosarcoma cell sublines with low and high metastatic potential have been described and characterized for their biochemical and invasive properties, and oncogenes expression $[18,19,36]$, the aim of this work was to evaluate by image analysis the DNA content and nuclear structure of these cell sublines in order to identify possible changes in chromatin organization related to the metastatic potential of these cells.

\section{Materials and methods}

\subsection{Cell lines}

RMS 9-4 is a rhabdomyosarcoma induced by an i.m. injection of $20 \mathrm{mg}$ of colloidal nickel into the thigh of a WAG rat [44]. The primary tumor was excised when it attained a $20 \mathrm{~mm}$ diameter, tumor tissue minced in Phosphate Buffered Saline (PBS), then dissociated in $0.25 \%$ trypsin. The parental cell line (F-9-4/0) was obtained and maintained in Dulbecco's Modified Eagle's Medium (DMEM) supplemented with $10 \%$ Fetal Calf Serum (FCS) [44]. This parental cell line was subcloned using several cloning methods: $\mathrm{E}$ and $\mathrm{F}$ lines were isolated in liquid medium by seeding one cell per well in 96-well microplates. Wells containing two or more colonies were eliminated. The selected colonies were expanded to obtain cell lines. Four cell lines called E-13a2, F-9-4/6, F-9$4 / 8$, and F-9-4/21 were used in this work [19,36,44]. $\mathrm{J}$ line (J-9-4/1) was isolated in semi-solid medium by plating cells $(10$ cells $/ \mathrm{ml})$ in $0.5 \%$ agarose. Isolated colonies were picked from the gel and expanded in liquid medium $[35,44]$.

A metastatic score was calculated for each cell line as the median number of pulmonary metastases observed on the lungs of rats grafted subcutaneously with $10^{5}$ cells from the different clones. A minimum of 20 rats were grafted for each cell clone.

For in vitro growth measurements, cells were plated at 50,000 cells/60-mm plate in standard growth medium. Duplicate plates were trypsinised, and the cells were counted using a Coulter counter (Coultronics, France) every $24 \mathrm{hr}$.
For chromosome numbers evaluation, $10^{6}$ cells were treated with colchicine $(5 \mathrm{mg} / \mathrm{ml}$ in DMEM). Cells were trysinised and centrifuged. The cell pellet was suspended in $\mathrm{KCl}$ hypotonic solution for $15 \mathrm{~min}$ at $37^{\circ} \mathrm{C}$. The cells were then rinsed and fixed in absolute methanol and glacial acetic acid $(3: 1, \mathrm{v} / \mathrm{v})$, smeared on a cold wet slide, gently flame dried and stained for 10 min with $2 \%$ Giemsa stain. 100 metaphases were counted for each cell line [19].

\subsection{DNA staining}

Cells in the exponential growth phase were grown on microscope slides (Labtek microchambers, Poly Labo, Strasbourg, France) and air dried. Cell smears were fixed in alcohol/formalin mixture $(3: 1)$ for $10 \mathrm{~min}$. Hydrolysis was performed in $5 \mathrm{~N} \mathrm{HCl}$ during $30 \mathrm{~min}$ at $22^{\circ} \mathrm{C}$. The cells were then stained in freshly prepared Schiff's reagent (pararosanilin chloride, CI 42500, Gurr, BDH, Poole, UK, $0.5 \%$ (w/v) in sulphite water) for $2 \mathrm{~h}$ in the dark at $22^{\circ} \mathrm{C}$. After rinsing in sulphite water and distilled water, the samples were mounted in acryptol (refraction index: 1.5, Surgipath, Richmond, Canada).

\subsection{Image cytometry}

This study was performed with a computer-assisted image analysis system (SAMBA 200, Unilog, Grenoble, France), the organization of which has been already described [4]. At least 400 cells were measured on each slide. Fields of observation were selected randomly from the middle part of the slide on a checkerboard basis. Cells of interest were therefore localized at low resolution by an image segmentation process through optical density thresholds, shape, and size criteria. The image acquisition in color involved a high resolution scanning through three successive red, green, and blue broadband filters. The analysis module includes a photomultiplier tube associated to a mirror scanner. A $\times 60$ (NA 0.8 ) objective was used, leading to a $0.63 \times 0.63 \mu \mathrm{m}$ pixel size. Images of $64 \times 64$ pixels were digitized. The significant densitometric resolution was 128 gray levels per color channel owing to the photomultiplier tube used as the light detector.

Eighteen parameters were computed from each nuclear image and subdivided into three groups of features: Three size and shape features, the Nuclear Area (NA), Nuclear Perimeter (NP) and Form Factor (FF); Five densitometric features include Integrated and Mean Optical Densities (IOD and MOD) and three 
descriptors of the individual cell nuclei OD histogram distribution (standard deviation (SDODH), skewness $(\mathrm{SODH})$, and kurtosis (KODH) of the density histogram). The distribution of nuclei according to IOD was plotted to provide cell cycle distribution estimates. The margins defining $\mathrm{G}_{0} \mathrm{G}_{1}$ and $\mathrm{G}_{2}$ peaks were sited as modal IOD $\pm 15 \%$ [9]. At least 100 reference cells (mouse hepatocytes or human lymphocytes) were measured in the same conditions for the calibration of the normal diploid (2c) value. The DNA-Malignancy Grade (DNA-MG) was calculated according to Böcking et al. [3].

Nine textural parameters were calculated on the nuclear image after reduction to 16 gray levels by linear rescaling. Four features were calculated on the graylevels co-occurrence matrix: Local Mean (LM), Entropy (ENT), Variation of Matrix Coefficients (VAC), and Contrast $(\mathrm{K})$. Five parameters were calculated on the run-length matrix: Short Run-Length Emphasis (SRE), Long Run-Length Emphasis (LRE), Grey Levels Distribution (GLD), Run-Length Distribution (RLD), and Run-Length Percentage (RPC) [4].

\subsection{Data analysis and statistics}

Univariate analysis was used to obtain the distribution, mean, and SD of the nuclear parameters for each cell population. For a given parameter, histograms were computed and significance of the differences between parameter values from various cell populations was calculated using one-way analysis of variance after Bonferroni correction for multiple groups and variables. Two main kinds of multidimensional analyses were used: supervised classification by discriminant analysis and nonsupervised classification. The linear stepwise discriminant analysis was based on use of the $F$-test to select variables. The classification rates of the cells into predicted groups were estimated by splitting the data sets into two equal parts, defined as learning and test sets. In these estimations, discriminant functions were obtained on learning groups only and test groups classified on these bases. This discriminant analysis could be complemented by a canonical analysis. This feature reduction technique derives canonical variables, which are linear combinations of the independent quantitative variables. Such variables are used to summarize discrimination between the different classification groups. Usually the first canonical variable is the most important in that it shows the highest variation between the groups [17]. The unsupervised multidimensional partitioning made it possible to separate cell classes that were different with respect to the distribution of parameters. This analysis successively looked for the most heterogeneously distributed feature, split the population into subgroups on the basis of the Fisher-Snedecor test and fused the groups which are not significantly different for the whole set of parameters. This process is iterated for all the parameters. This program functions step by step, where each step leads to a new partition from the preceding partition. It did not entail any a priori knowledge about the different types eventually to be found; it also preserves total objectivity about the status of a given cell [8].

\section{Results}

\subsection{DNA content of cell sublines}

The DNA content of the different cell sublines was estimated by measurement of the IOD of cell nuclei stained by the Feulgen method. Histograms were computed from IOD values as previously described. DNA-MG was calculated on these histograms. Cell cycle phases were also extracted by isolation of the $\mathrm{G}_{0} / \mathrm{G}_{1}$ and $\mathrm{G}_{2}$ peaks according to Material and methods. $S$ phase and $>\mathrm{G}_{2}$ cells were estimated on the remaining cells. Table 1 shows the results of these analyses. No correlation could be found between metastatic score and chromosome number, or doubling time, or the DNA histogram derived values. Two cell sublines: E-13a2, and F-9-4/21, displayed a distribution of cells within the cycle phases different from that observed in the parental F-9-4/0 population.

\subsection{Variations of the other features extracted by image analysis}

Only one parameter (SDODH) displayed a significative correlation with the metastatic score (Pearson correlation coefficient: $r=0.934 ; p<0.05$ by $t$-test after Bonferroni correction for multiple variables). The increase in metastatic score is characterized by the appearance of dense nuclei evidenced by the decrease of $\mathrm{KODH}$ with an increased heterogeneity of chromatin condensation degrees (increase in SDODH). This is confirmed by the decreases of both EN and VAC which are related with a more condensed chromatin organization [15]. At the geometric level, no changes could be evidenced in the clones analyzed. 
Table 1

DNA distribution characteristics in cell sublines

\begin{tabular}{|c|c|c|c|c|c|c|c|c|c|}
\hline \multirow{2}{*}{$\begin{array}{l}\text { Cell } \\
\text { subline }\end{array}$} & \multirow{2}{*}{$\begin{array}{l}\text { Number } \\
\text { of cells }\end{array}$} & \multirow{2}{*}{$\begin{array}{c}\text { Metastatic } \\
\text { score }\end{array}$} & \multirow{2}{*}{$\begin{array}{c}\text { Chromosome } \\
\text { number }\end{array}$} & \multirow{2}{*}{$\begin{array}{l}\text { Doubling } \\
\text { time (hrs) }\end{array}$} & \multirow{2}{*}{$\begin{array}{l}\text { DNA-IOD } \\
\text { modal value }\end{array}$} & \multirow[t]{2}{*}{ DNA-MG } & \multicolumn{3}{|c|}{$\%$ Cells in cycle phase } \\
\hline & & & & & & & $\mathrm{G}_{0} / \mathrm{G}_{1}$ & $\mathrm{~S}$ & $\mathrm{G}_{2}$ \\
\hline F-9-4/8 & 424 & 2 & 68 & 21 & 2.0 & 1.85 & 82 & 5 & 13 \\
\hline E-13a2 & 447 & 3 & 62 & 18 & 1.35 & 1.28 & 50 & 25 & 25 \\
\hline F-9-4/6 & 448 & 4 & 76 & 15 & 1.8 & 1.60 & 82 & 5 & 13 \\
\hline F-9-4/21 & 439 & 4 & 79 & 27 & 1.8 & 1.77 & 66 & 19 & 15 \\
\hline F-9-4/0 & 446 & 7 & 78 & 20 & 2.0 & 1.72 & 85 & 5 & 10 \\
\hline $\mathrm{J}-9-4 / 1$ & 439 & 7 & 80 & 13 & 1.8 & 1.84 & 76 & 10 & 14 \\
\hline
\end{tabular}

DNA content was estimated by measuring Integrated Optical Density (IOD) on Feulgen-stained nuclei. DNA-IOD modal value, DNA-MG and cell cycle distribution were computed from IOD histograms. 4 to 6 measurements for each cell line. DNA-IOD modal value is expressed in c, DNA-MG is expressed in arbitrary units. Cycle phases distributions in E-13a2 and F-9-4-21 cell lines were significantly different from F-9-4/0 parental cells $\left(p<0.05, \chi^{2}\right.$ test).

Table 2

Ranking of the best discriminant parameters and calculation of the canonical variable

\begin{tabular}{lcc}
\hline Parameter & $\begin{array}{c}\text { Discriminatory } \\
\text { power }\end{array}$ & $\begin{array}{c}\text { Coefficient of } \\
\text { canonical variable }\end{array}$ \\
\hline SDODH & 93.7 & 14.6 \\
SODH & 58.5 & 12.4 \\
K & 50.2 & 0.13 \\
RLD & 35.7 & 3.80 \\
FF & 7.9 & 70.6 \\
LM & 7.8 & 3.80 \\
\hline
\end{tabular}

The most discriminant features were selected after linear discriminant analysis applied to cell sublines populations.

\subsection{Mutivariate analysis}

However, since all computed parameters might be involved in the definition of a nuclear cytological phenotype, multivariate methods should be used for cell sublines characterization. In an attempt to select the features enabling the better separation between these sublines, linear discriminant analysis was performed. The most discriminant features, ranked according to their discriminatory power ( $F$ to remove values after incorporation into discriminant functions), appeared on Table 2. Except for FF, all the selected features were related to the nuclear texture, either derived from the OD histogram (SDODH, SODH), from the cooccurrence matrix (LM, K), or from the run-length matrix (RLD). Although the $F$ test does not necessarily identify the best discriminant image cytometry features, among these parameters, one with the highest $F$ to enter value (SDODH) was strongly correlated to metastatic score. This analysis was followed by a canonical transformation of data by combination of the most discriminant parameters pondered by calculated coefficients (Table 2). The mean values of the first canonical variable (which accounts for $64.9 \%$ of the variance between the groups) were calculated in each cell clone and appear on Fig. 1. A correlation could be seen between the first canonical variable values and the metastatic score ( $r=0.899 ; p=0.0147)$. On the contrary, the variations in the second canonical variable (which accounts for $23.4 \%$ of the variance) were independent from the metastatic score $(r=0.260$; NS).

\subsection{Subclassification of cells}

Finally, these changes encountered in various cell sublines could be objectively evaluated by an unsupervised classification of cells. All data from cell sublines were merged in a unique group of cells. This resulting cell population was submitted to unsupervised multidimensional partitioning. This method partitioned the cells into two significant cell subgroups called "A" and "B". The parameters selected by the classifier were four features already selected by their discriminatory power (Table 2), i.e., SDODH, SODH, K, and RLD. A discriminant analysis was computed using these A and $\mathrm{B}$ subsets as learning sets and the 6 constituting primary cell populations as test sets (Table 3 ). Type "A" cells were predominant in F-9-4/8 and E-13a2 clones with the lowest score. The frequency of this "A" subset decreased regularly as the score increased. On the contrary, the frequency of type "B" cells increased with the score value. The values of the individual parameters in these 2 subsets appear on Table 4. Type "B" cells differ from type "A" by a more globally condensed chromatin (increase in MOD, SDODH, decrease in LM) with a more heterogeneous distribution of chromatin spots (decrease in GLD). Concerning DNA content, type " $\mathrm{B}$ " cells displayed a higher mean DNA-IOD value, with an aneuploidy evidenced by a higher fre- 


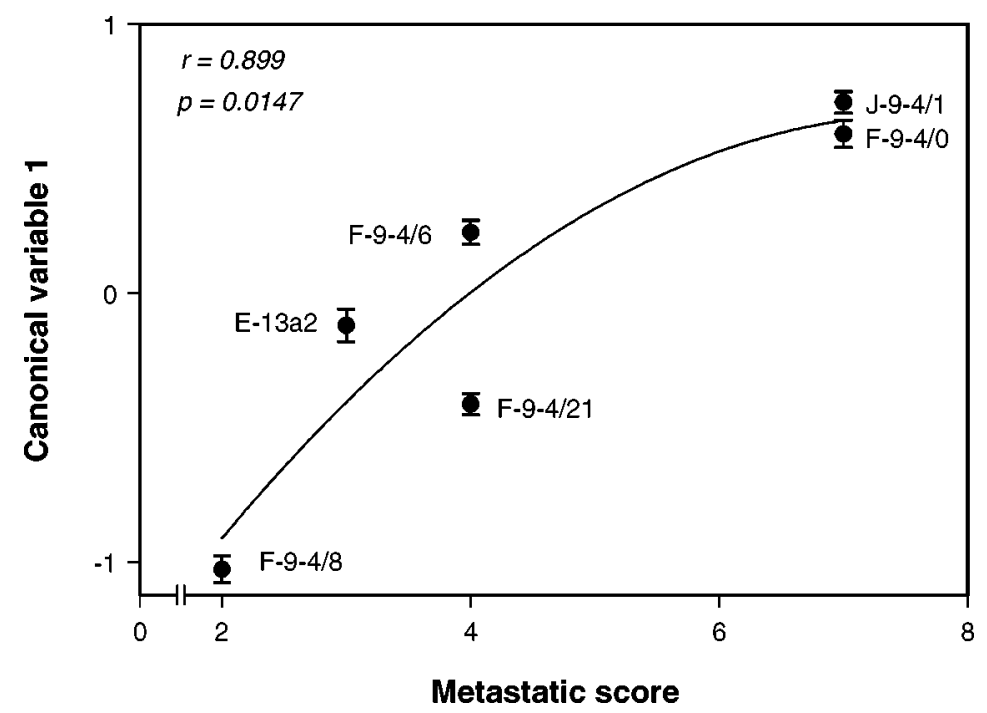

Fig. 1. Value of the first canonical variable in the different cell sublines as a function of the metastatic score. The variable was calculated for each cell using the parameters and the coefficients listed in Table 2. Each point represents mean \pm SD of a given cell subpopulation.

Table 3

Distribution of cells from the various clones among the two subsets defined after unsupervised partitioning of the whole cell population

\begin{tabular}{llcc}
\hline \multirow{2}{*}{$\begin{array}{l}\text { Rell } \\
\text { population }\end{array}$} & $N$ & \multicolumn{2}{c}{ \% Cells classified in subsets } \\
\cline { 3 - 4 } F-9-4/8 & & A & B \\
E-13a2 & 424 & 80 & 20 \\
F-9-4/6 & 448 & 81 & 19 \\
F-9-4/21 & 439 & 40 & 30 \\
F-9-4/0 & 446 & 45 & 52 \\
J-9-4/1 & 439 & 43 & 55 \\
\hline
\end{tabular}

Subsets were generated from the whole cell population obtained by merging files of all clones. Distribution was estimated by discriminant analysis using generated subsets as learning sets and original clones as test sets. $N$ : Numbers of cells in each experimental group. For F-9-4-8, E-13a2 and F-9-4-6 cell populations, the distributions of cells within subsets are significantly different from parental F-9$4 / 0$ cell line $\left(p<0.0001, \chi^{2}\right.$ test). Number of type B cells in population is positively correlated to the metastatic score $(r=0.867$, $p=0.025)$.

quency of $>5$ c cells $(27.8 \%$ vs. $18.7 \%$ in "A"cells) and a significant number of $>8 \mathrm{c}$ cells $(3.3 \%$ vs. absence in "A" cells).

\section{Discussion}

The issue we address in the work reported here is whether the metastatic ability of in vitro selected sublines of rat rhabdomyosarcoma cells is associated with nuclear DNA content, shape, or texture changes eval-
Table 4

Parameters values in subsets obtained from unsupervised partitioning of cells

\begin{tabular}{lccc}
\hline \multirow{2}{*}{ Parameter } & \multicolumn{2}{c}{ Parameter value } \\
\cline { 2 - 4 } IOD & Subset A & Subset B & $t$ \\
MOD & $4389 \pm 214$ & $4824 \pm 306$ & 2.351 \\
SODH & $5.7 \pm 0.2$ & $6.5 \pm 0.2$ & $4.696^{*}$ \\
SDODH & $185 \pm 9$ & $-26.3 \pm 6.9$ & 0.814 \\
KODH & $300 \pm 11$ & $218 \pm 10$ & $4.488^{*}$ \\
LM & $537 \pm 14$ & $512 \pm 15$ & 2.287 \\
E & $2415 \pm 319$ & $2090 \pm 281$ & 1.423 \\
VAC & $1919 \pm 302$ & $1608 \pm 232$ & 1.489 \\
K & $6747 \pm 443$ & $6452 \pm 469$ & 0.877 \\
SRE & $3549 \pm 135$ & $3444 \pm 147$ & 1.012 \\
LRE & $318 \pm 14$ & $310 \pm 17$ & 0.722 \\
GLD & $6139 \pm 275$ & $5726 \pm 298$ & 1.957 \\
RLD & $674 \pm 26$ & $651 \pm 28$ & 1.163 \\
RPC & $1089 \pm 41$ & $1061 \pm 47$ & 0.868 \\
NA & $727 \pm 27$ & $711 \pm 33$ & 0.725 \\
NP & $89.8 \pm 2.9$ & $87.8 \pm 2.4$ & 1.000 \\
FF & $10.8 \pm 0.5$ & $10.5 \pm 0.4$ & 0.751 \\
\hline Paramets & -22.4 & \\
\hline
\end{tabular}

Parameters values are expressed as mean $\pm 95 \%$ confidence interval. ${ }^{*} p<0.05$; significance of differences between subsets were calculated using Student $t$-test after Bonferroni correction for multiple variables.

uated by image cytometry. The cells from the $6 \mathrm{ob}-$ served sublines exhibited differences in experimental metastatic capacity. The DNA-IOD, a feature directly related to DNA content, was unrelated to the metastatic score observed. Some sublines exhibited significant 
changes in the distribution of cells within the cell cycle phases, with an increase of the percentages of $S$ and $G_{2}$ cells. However, these changes occurring in clones E13a2, and F-9-4/21 seem unrelated to metastatic ability. These data suggested that measurements of DNA content and DNA-ploidy could not be regarded as discriminant in the identification of metastatic sublines in this system. Different data have been reported in variant cell lines of the B16 murine melanoma [16]. Literature data indicated that DNA-ploidy could be regarded as a significant predictive parameter for metastasis in prostate carcinomas [40], breast [13], stomach [41,46], and colorectal cancers [22], but less in head and neck cancers [45], or rhabdomyosarcomas [21].

Other features computed by image analysis in this work concerned nuclear shape and size, and chromatin texture. Variations in geometric features seem to be present among the various clones, as FF has been selected in discriminant analysis, but appear independent from the metastatic score. Similar data have been observed in breast cancer, where nuclear morphometric features did not predict successfully which patients would have recurrent disease [32]. On the contrary, such variations in nuclear morphometry have been previously observed in other tumors. In malignant fibrous histiosarcomas, these morphometric features appeared as the most useful for prediction of distant recurrence [2]. Similarly, nuclear area, perimeter and roundness were found to correlate significantly with predictive potential for metastases in ovarian granulosa cell tumors or in prostatic carcinomas [30]. In bladder carcinoma, the mean nuclear volume, as measured by stereological methods appears as the most important prognostic indicator for recurrence [12].

Concerning chromatin supraorganization, alterations occurred in the evaluated cell sublines as assessed by nuclear texture analysis. Globally, cell sublines with increased metastatic potential displayed a more condensed chromatin with a higher heterogeneity of chromatin clumps. Increased chromatin condensation and heterogeneity has previously been described in soft tissue tumors that developed a metastasis as compared to tumors free of metastasis until 38 months after the diagnosis [39]. Similarly, alterations in chromatin texture and numbers of chromatin particles have been identified as discriminant features for identification of breast tumors with metastatic spread [24].

The significance of these nuclear textural changes are not fully understood, but progressive loss of shaperesponsive controls may be an important factor in tumor progression [33]. As chromatin condensation has been associated to gene inactivity, it could be suggested that an increase of tumor aggressiveness or metastatic ability is accompanied by a progressive limited transcription of the genome [31]. DNA methylation has been proposed as a candidate for explaining chromatin condensation states [27] and it has been shown that methylation processes interfere with the metastatic function of rhabdomyosarcoma cells used in this study [36]. However, cell proliferation could influence chromatin condensation and the changes observed could be related to some increase or decrease of cell cycle phases in the sublines. This was rather unlikely for the analyzed cell sublines whose cycle distributions appeared independent from the metastatic potential. Another possibility would be the presence of alterations in the structure of the nuclear matrix which could serve an important role in DNA organization and chromatin texture. Changes in nuclear matrix protein profiles have been previously observed in rat prostate [14] or breast cancer cells [20] together with an increased nuclear pleomorphism. Since matrix appears to play a key role in the topological arrangement of DNA and to act as a major structure in the maintenance of nuclear shape and organization [33] it would appear as another good candidate for explaining nuclear textural modifications in metastatic sublines. Moreover, recent data in our laboratory showed alterations in matrix distribution in the nuclei of drugresistant cells with $m d r l$ gene overexpression (data not shown).

Finally, whether oncogenes and/or tumor suppressor genes play a role in the definition of the nuclear phenotype of the tested sublines remains to be elucidated. Rhabdomyosarcoma cell lines either selected in vitro (F-9-4/0, F-9-4/21), or in vivo (NT4T and S4T sublines) have been previously analyzed [18]. C-myc, Haras, Ki-ras and erbB protooncogenes were activated regardless of the metastatic potential of sublines. On the contrary, overexpression of protooncogenes c-myc, Ha-ras, Ki-ras, c-jun, junB and fos in tumors derived from injection of these cell sublines into syngeneic rats could be related to the metastatic potential, except for Ha-ras, which is equally expressed everywhere. A role for these genes in chromatin condensation or nuclear aspect is not well known, but it has been suggested that ras transformation could result in alterations in chromatin supraorganization in mouse 3T3 cells [27,28] and c-myc expression has been shown to correlate with nuclear pleomorphism in human primary or metastatic renal carcinomas [23]. Moerover, it has been recently shown that transfections of mouse fibroblasts with $\mathrm{H}-$ 
ras and $\mathrm{v}$-fes confer metastatic potential, resulting in nuclear morphological changes, and induce the same changes in nuclear matrix proteins profile, regardless of transformation agent. These alterations were not induced by v-raf which failed to increase metastatic potential of cells [42].

In conclusion, these data suggest that, in rat rhabdomyosarcoma cell sublines, the metastatic ability could be associated with nuclear morphological changes, particularly at the chromatin texture level.

\section{Acknowledgements}

This work was supported by the Comités Départementaux des Ardennes et de l'Aube de la Ligue Nationale contre le Cancer. S.Y. was the recipient of a fellowship from Région Champagne-Ardenne.

\section{References}

[1] R. Barraclough, H.J. Davies, M.P. Davies, Y. Ke, B.H. Lloyd, A. Oates and P.S. Rudland, Use of DNA transfer in the induction of metastasis in experimental mammary systems, Biochem. Soc. Symp. 63 (1998), 273-294.

[2] R.L.J. Becker, D. Venzon, E.E. Lack, U.V. Mickel, S.W. Weiss and T.J. O'Leary, Cytometry and morphometry of malignant fibrous histiocytoma of the extremities. Prediction of metastasis and mortality, Am. J. Surg. Pathol. 15 (1991), 957-964.

[3] A. Boecking, R. Chatelain, M. Homge, R. Daniel, A. Gillisen and D. Wohltmann, Representativity and reproducibility of DNA malignacy grading in different carcinomas, Anal. Quant. Cytol. Histol. 11 (1989), 81-86.

[4] G. Brugal, Image analysis of microscopic preparations, Meth. Achiev. Exp. Pathol. 11 (1984), 1-33.

[5] I. Carr and N. Pettigrew, Will a tumor metastasize? Quantitate, semi-quantitate or pseudo-quantitate?, Int. J. Clin. Lab. Res. 22 (1992), 129-132.

[6] C.J. Cornelisse, H.R. de-Koning, A.J. Moolenaar, C.J. VandeVelde and J.S. Ploem, Image and flow cytometric analysis of DNA content in breast cancer: relation to oestrogen receptor content and lymph node involvement, Anal. Quant. Cytol. Histol. 4 (1984), 9-18.

[7] L.A. Culp, W. Lin, N.R. Kleinman, K.L. O'Connor and R. Lechner, Earliest steps in primary tumor formation and micrometastasis resolved with histochemical markers of genetagged tumor cells, J. Histochem. Cytochem. 46 (1998), 557568.

[8] J. Dufer, M.G. Akeli, P. Jeannesson, A. Desplaces and J.C. Jardillier, Quantitative morphological assessment of adriamycin-resistant human K562 leukemic cells, Cytometry 10 (1989), 37-43.
[9] J. Dufer, C. Millot-Broglio, Z. Oum'Hamed, F. LiautaudRoger, P. Joly, A. Desplaces and J.C. Jardillier, Nuclear DNA and chromatin texture in multidrug-resistant human leukemic cell lines, Int. J. Cancer 60 (1995), 108-114.

[10] I.J. Fidler, The biology of human cancer metastasis, Acta Oncol. 30 (1991), 669-675.

[11] L.S. Freedman, D.N. Edwards, E.M. McConnell and D.Y. Downham, Histological grade and other prognostic factors in relation to survival of patients with breast cancer, Br. J. Cancer 40 (1979), 44-55.

[12] S. Fukuzawa, T. Hashimura, M. Sasaki, H. Yamabe and O. Yoshida, Nuclear morphometry for improved prediction of the prognosis of human bladder cancer, Cancer 76 (1995), 1790-1796.

[13] P.H. Gann, S.A. Colilla, S.M. Gapstur, D.J. Winchester and D.P. Winchester, Factors associated with axillary lymph node metastasis from breast carcinoma: descriptive and predictive analyses, Cancer 86 (1999), 1511-1519.

[14] R.H. Getzenberg, K.J. Pienta, E.Y.W. Huang and D.S. Coffey, Identification of nuclear matrix proteins in the cancer and normal rat prostate, Cancer Res. 51 (1991), 6514-6520.

[15] F. Giroud, Approches cytométriques de la prolifération et de la différenciation. Notion de faciès chromatinien, Ph.D. Dissertation, 1987, University of Grenoble 1.

[16] F. Hallouche, A.E. Adams, O.R. Hinton, G. Relf, M.S. Lakshmi and G.V. Sherbet, Image processing for cell cycle analysis and discrimination in metastatic variant cell lines of the B16 murine melanoma, Pathobiology 60 (1992), 76-81.

[17] F. Hallouche, A.E. Adams, O.R. Hinton, D.P. Surtees, V. Wadehra and G.V. Sherbet, Discriminant analysis for classification of murine melanomas and human cervical epithelial cells, Anal. Quant. Cytol. Histol. 15 (1993), 50-60.

[18] N. Hanania, M.D. Boyano, C. Mangin and M.F. Poupon, Oncogene and mdr1 gene expression in rat rhabdomyosarcoma sublines of different metastatic potential, Anticancer Res. 11 (1991), 473-480.

[19] O. Haus, C. Pauwels, M.F. Poupon and R. Berger, Chromosome analysis of rat tumor cell lines associated with metastatic potential and drug resistance, Invasion Metastasis 6 (1986), 180-196.

[20] P.S. Khanuja, J.E. Lehr, H.D. Soule, S.K. Gehani, A.C. Noto, S. Choudhuri, R. Chen and K.J. Pienta, Nuclear matrix proteins in normal and breast cancer cells, Cancer Res. 53 (1993), 3394-3398.

[21] S.E. Kilpatrick, L.A. Teot, K.R. Geisinger, P.L. Martin, D.K. Shumate, N. Zbieranski, G.B. Russell and C.D.M. Fletcher, Relationship of DNA ploidy to histology and prognosis in rhabdomyosarcoma. Comparison of flow cytometry and image analysis, Cancer 74 (1994), 3227-3233.

[22] O. Kimura, T. Kijima, S. Moriwaki, K. Hoshino, M. Yonekawa, A. Sugezawa and N. Kaibara, DNA index as a significant indicator of lymph node metastasis and local recurrence of rectal cancer, Dis. Colon Rectum 35 (1992), 1130-1134.

[23] T. Kinouchi, S. Saiki, T. Naoe, A. Uenaka, T. Kotabe, H. Shiku and E. Nakayama, Correlation of c-myc expression with nuclear pleomorphism in human renal cell carcinoma, Cancer Res. 49 (1989), 3627-3630. 
[24] K.D. Kunze, G. Haroske, V. Dimmer, W. Meyer and F. Theissig, Kernbildanalytische Untersuchungen zur Heterogenität, Proliferation und Metastasierung maligner Tumoren, Acta Histochem. 39(Suppl.) (1990), 147-154.

[25] M.S. Lakshmi and G.V. Sherbet, Measurement of DNA content and nuclear pleomorphism in metastatic variants of the B16 murine melanoma and hamster lymphoma and its liver metastasis using image analysis techniques, Clin. Exp. Metastasis 8 (1990), 553-566.

[26] A. Maiorana, V. Cavallari, M.C. Maiorana, R.A. Fano, S. Scimone, R. Fante and S. Garbisa, Metastatic capacity and differentiation in murine melanoma cell lines. A morphometric study, Path. Res. Pract. 188 (1992), 657-662.

[27] M.L.S. Mello and A.F. Chambers, Image analysis of Feulgenstained transformed NIH 3T3 cells differing in p21 expression and ras-induced metastatic ability, Anal. Quant. Cytol. Histol. 16 (1994), 113-123.

[28] M.L.S. Mello, S. Contente, B.C. Vidal, W. Planding and U. Schenk, Modulation of the ras transformation affecting chromatin supraorganization as assessed by image analysis, Exp. Cell Res. 220 (1995), 374-382.

[29] M.L.S. Mello and J. Russo, Image analysis of Feulgen-stained c-H-ras-transformed NIH/3T3 cells, Biochem. Cell Biol. 68 (1990), 1026-1031.

[30] P. Narayan, M. Michael, P. Jajodia, R. Stein, J. Gonzalez, B. Ljung, K. Chu and B. Mayall, Automated image analysis. A new technique to predict metastatic potential of prostate carcinomas? (Meeting abstract), J. Urol. 141 (1989), 183A.

[31] C. Nicolini, M. Grattarola, F. Beltrame and F. Kendall, Coupling of nuclear morphometry to cell geometry: its role in the control of normal and abnormal cell growth, in: Cell Growth, C. Nicolini, ed., Plenum Press, New York, 1982, pp. 587-607.

[32] K.J. Pienta and D.S. Coffey, Correlation of nuclear morphometry with progression of breast cancer, Cancer $\mathbf{6 8}$ (1991), 20122016.

[33] K.J. Pienta, A.W. Partin and D.S. Coffey, Cancer as a disease of DNA organization and dynamic cell structure, Cancer Res. 68 (1989), 2012-2016.

[34] G. Poste, J. Doll, A.E. Brown, J. Tzeng and I. Zeidman, Comparison of the metastatic properties of B16 melanoma clones isolated from cultured cell lines, subcutaneous tumors, and individual lung metastases, Cancer Res. 42 (1982), 2770-2778.

[35] J. Pot-Deprun, M.F. Poupon, F.L. Sweeney and I. Chouroulinkov, Growth, metastasis, immunogenicity, and chromosomal content of a nickel-induced rhabdomyosarcoma and subsequent cloned cell lines in rats, J. Natl. Cancer Inst. 71 (1983), $1241-1245$
[36] M.F. Poupon, The metastatic function of cancer cells as revealed by a rat sarcoma model, Cancer Rev. 5 (1986), 50-82.

[37] M.F. Poupon, De la cellule tumorale à la métastase, Bull. Cancer 80 (1993), 5-10.

[38] J.T. Price, M.T. Bonovich and E.C. Kohn, The biochemistry of cancer dissemination, Crit. Rev. Biochem. Mol. Biol. 32 (1997), 175-253.

[39] M. Remmelink, I. Salmon, M. Petein, S. Henrion, J.L. Pasteels and R. Kiss, Computer-assisted quantitative description of chromatin pattern in soft tissue tumors of the adult, Am. J. Clin. Pathol. 102 (1994), 780-787.

[40] J.S. Ross, T. Nazeer, K. Church, C. Amato, H. Figge, M.D. Rifkin and H.A. Fisher, Contribution of HER-2/neu oncogene expression to tumor grade and DNA content analysis in the prediction of prostatic carcinoma metastasis, Cancer $\mathbf{7 2}$ (1993), 3020-3028.

[41] A. Russo, V. Bazan, M. Migliavacca, I. Zanna, C. Tubiolo, F.M. Tumminello, G. Dardanoni, M. Cajozzo, P. Bazan, G. Modica, M. Latteri, R.M. Tomasino, G. Colucci, N. Gebbia and G. Leto, Prognostic significance of DNA ploidy, S-phase fraction, and tissue levels of aspartic, cysteine, and serine proteases in operable gastric carcinoma, Clin. Cancer Res. 6 (2000), 178-184.

[42] S.K. Samuel, T.M. Minish and J.R. Davie, Altered nuclear matrix protein profiles in oncogene-transformed mouse fibroblasts exhibiting high metastatic potential, Cancer Res. 57 (1997), 147-151.

[43] B. Stenkvist, S. Westman-Naeser, J. Holmquist, B. Nordin, E.M. Bengtston and J. Vepelius, Computerized nuclear morphology as an objective method for characterizing human cancer cell populations, Cancer Res. 38 (1978), 4688-4697.

[44] F.L. Sweeney, J. Pot-Deprun, M.F. Poupon and I. Chouroulinkov, Heterogeneity of the growth and metastatic behavior of cloned cell lines derived from a primary rhabdomyosarcoma, Cancer Res. 42 (1982), 3776-3782.

[45] J. Wennerberg, B. Baldetorp and P. Wahlberg, Distribution of non-diploid flow-cytometric DNA indices and their relation to the nodal metastasis in squamous cell carcinomas of the head and neck, Invasion Metastasis 18 (2000), 184-191.

[46] Y. Yonemura, L. Fonseca, K. Tsugawa, I. Ninomiya, H. Matsumoto, K. Sugiyama, S. Ohoyama, S. Fushida, H. Kimura and I. Miyazaki, Prediction of lymph node metastasis and prognosis from the assay of the expression of proliferating cell nuclear antigen and DNA ploidy in gastric cancer, Oncology 51 (1994), 251-257. 


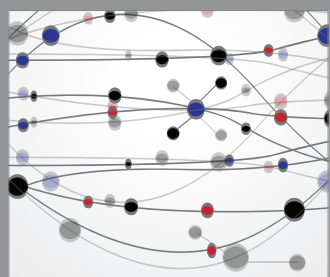

The Scientific World Journal
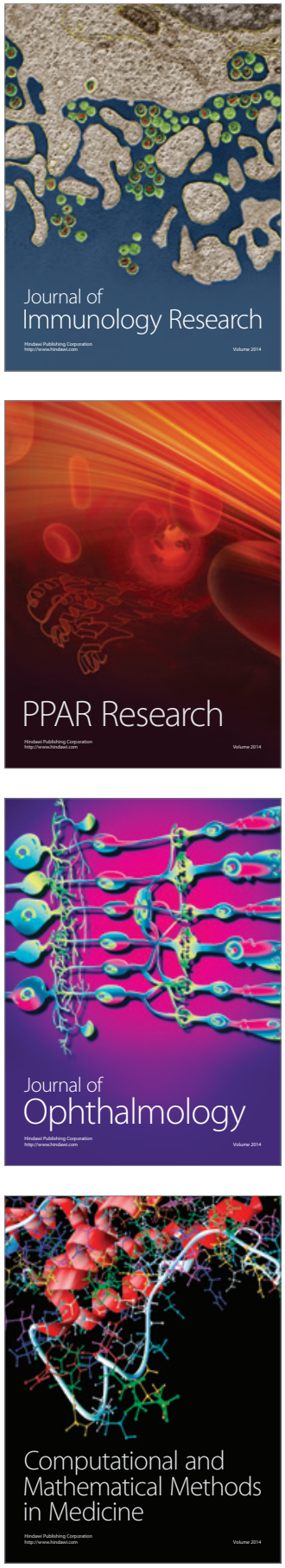

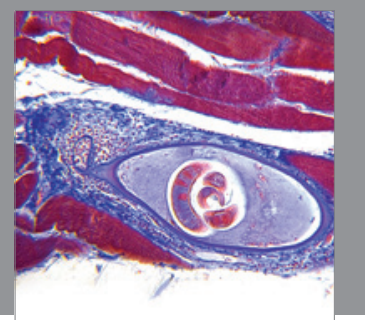

Gastroenterology

Research and Practice
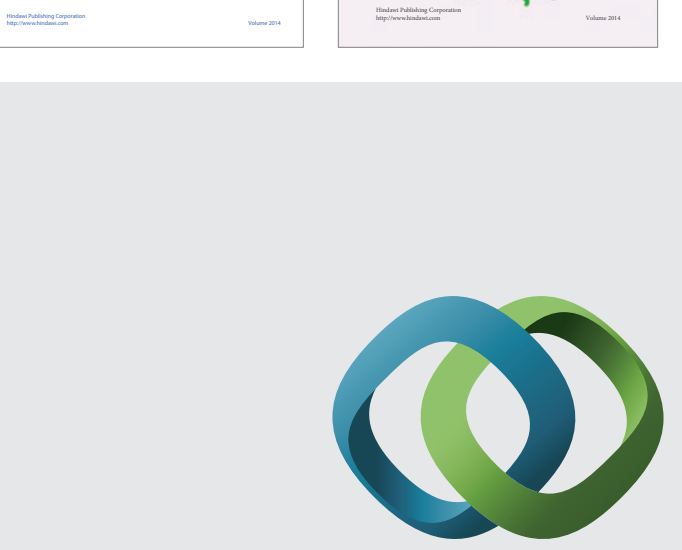

\section{Hindawi}

Submit your manuscripts at

http://www.hindawi.com
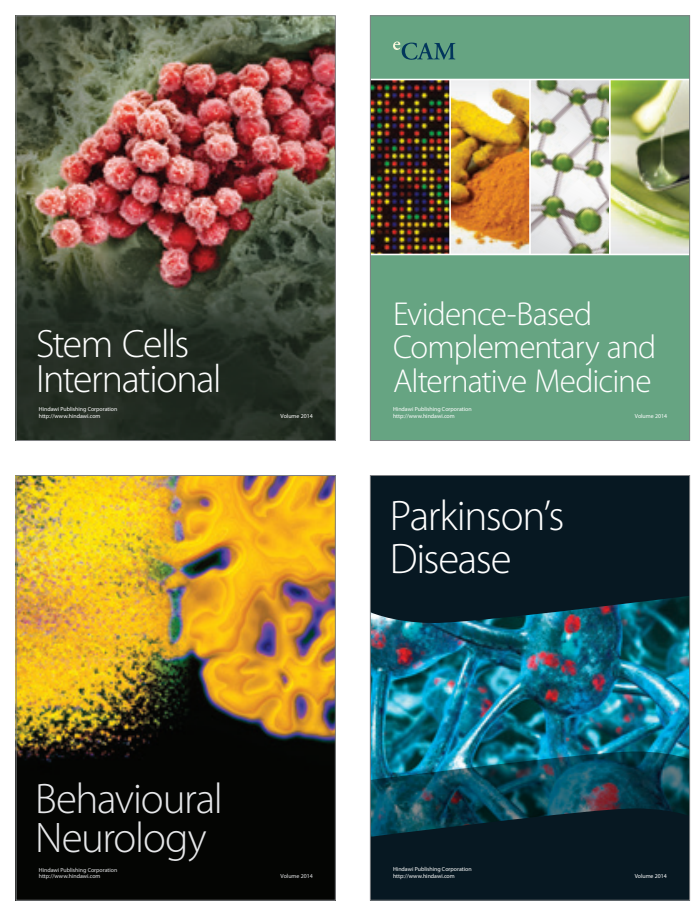

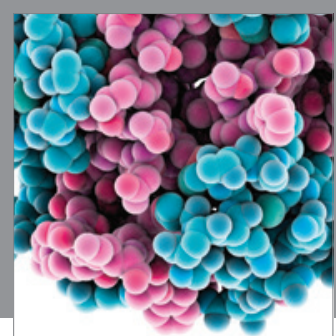

Journal of
Diabetes Research

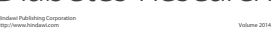

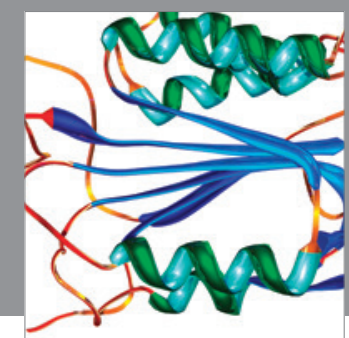

Disease Markers
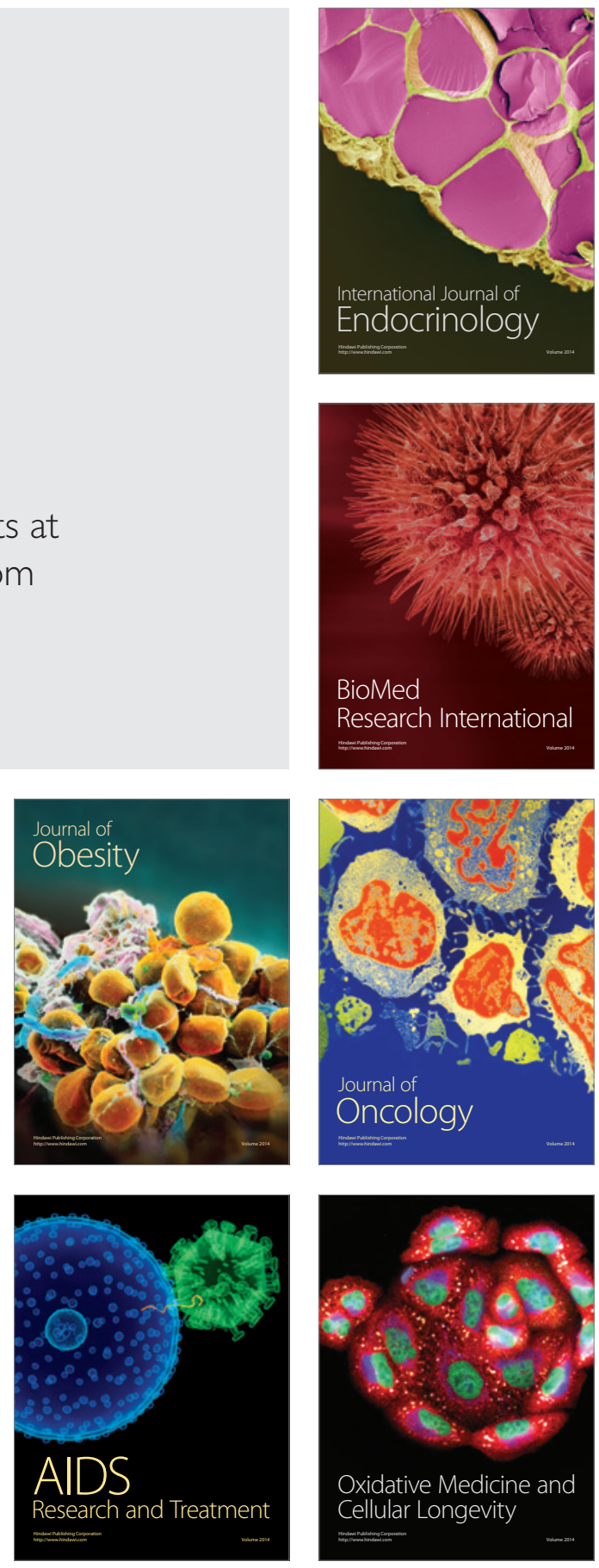